This item was submitted to Loughborough's Institutional Repository (https://dspace.lboro.ac.uk/) by the author and is made available under the following Creative Commons Licence conditions.

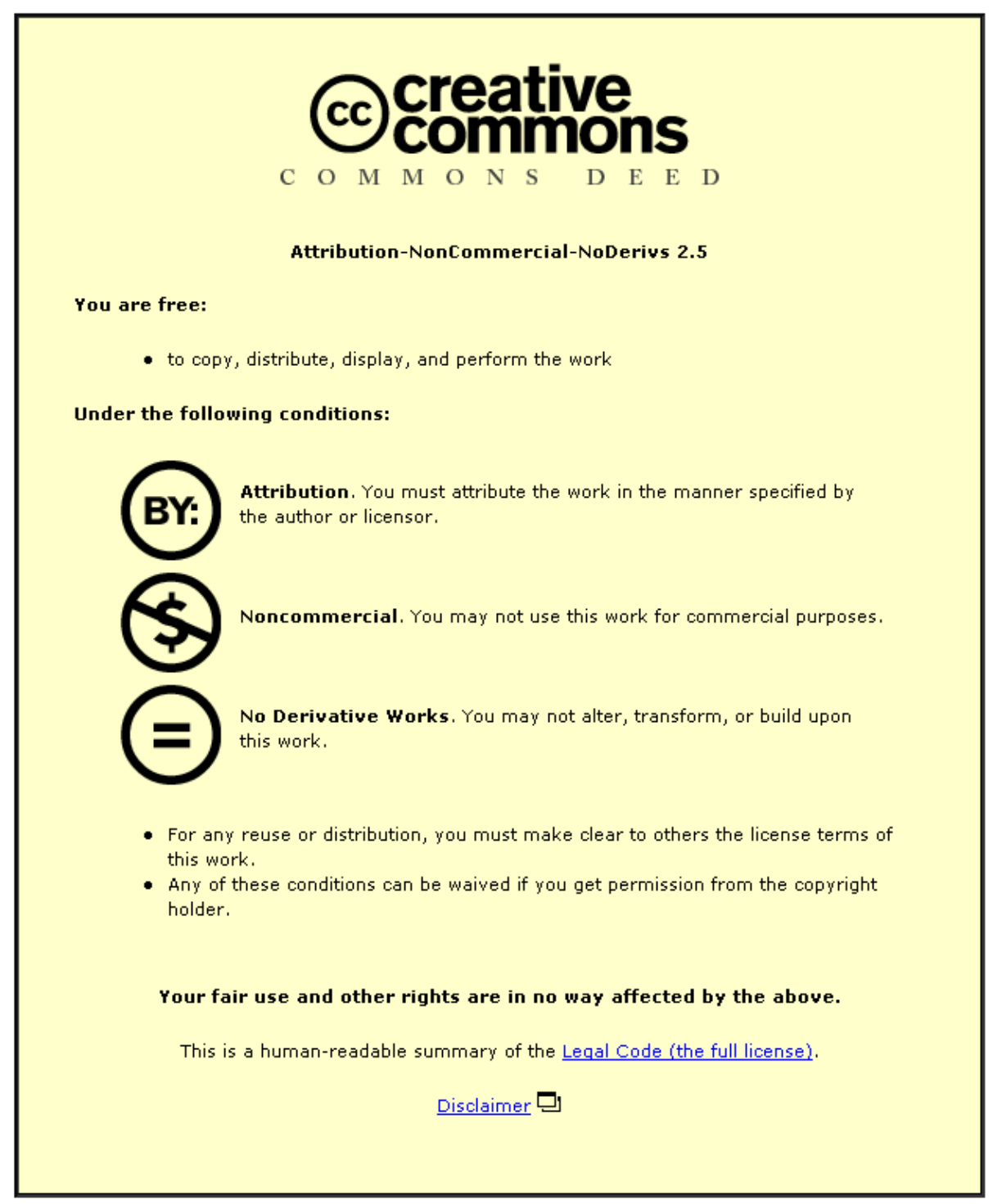

For the full text of this licence, please go to: http://creativecommons.org/licenses/by-nc-nd/2.5/ 


\title{
Subject-specific computer simulation model for determining elbow loading in one-handed tennis backhand groundstrokes
}

\author{
${ }^{1}$ M.A. King, ${ }^{2}$ J.A. Glynn, and ${ }^{3}$ S.R. Mitchell \\ ${ }^{1}$ School of Sport, Exercise and Health Sciences, Loughborough University, LE11 3TU, UK. \\ ${ }^{2}$ ASPIRE Academy for Sports Excellence, P.O. Box 22287, Doha, Qatar. \\ ${ }^{3}$ Wolfson School of Mechanical and Manufacturing Engineering, Loughborough University, LE11 3TU, UK.
}

\begin{abstract}
A subject-specific angle-driven computer model of a tennis player, combined with a forward dynamics, equipment-specific computer model of tennis ball/racket impacts was developed to determine the effect of ball/racket impacts on loading at the elbow for onehanded backhand groundstrokes. Matching subject-specific computer simulations of a typical topspin/slice one-handed backhand groundstroke performed by an elite tennis player were determined with root mean square differences between performance and matching simulations of less than $0.5^{\circ}$ over a $50 \mathrm{~ms}$ period starting from ball impact. Simulation results suggest that for similar ball/racket impact conditions, the difference in elbow loading for a topspin and slice one-handed backhand groundstroke is relatively small. In this study, the relatively small differences in elbow loading may be due to comparable angle-time histories at the wrist and elbow joints with the major kinematic differences occurring at the shoulder. Using a subject-specific angle-driven computer model combined with a forward dynamics, equipment-specific computer model of tennis ball/racket impacts allows peak internal loading, net impulse and shock due to ball/racket impact to be calculated which would not otherwise be possible without impractical invasive techniques. This study provides a basis for further investigation of the factors that may increase elbow loading during tennis strokes.
\end{abstract}

Keywords: tennis, backhand, elbow loading, simulation.

\section{Introduction}

Determining internal loading during dynamic sports movements is a difficult and challenging problem with traditional inverse dynamics methods under the assumption of rigid link segments which fail to account for the effects of soft tissue motion (Pain and Challis, 2006). For activities including impacts, the inclusion of wobbling masses within the model is crucial as the loading on the system can be up to $50 \%$ lower for a wobbling mass model compared to the equivalent rigid segment model. Angle-driven computer simulation models incorporating wobbling masses combined with force plate data have been used to determine internal loading during dynamic jumping movements (Wilson, King and Yeadon, 2006; King, Wilson and Yeadon, 2006). In tennis, determining internal loading has the added complication of the interaction between the ball/racket and player to be accounted for with it being critical that accurate force data is input to the arm from the ball/racket impact.

The backhand groundstroke, together with the forehand and service, form the cornerstone of tennis stroke production (Elliott, Marsh and Overheu, 1989). Historically, the backhand has been defined as the stroke that causes the back of the hand to be facing the opponent when striking the ball (Roetert and Groppel, 2001). The emergence and popularity of the two-handed backhand groundstroke has led to a more general definition that a backhand is the stroke where the ball approaches on the left side of a right-handed player. It is widely accepted that the one-handed 
backhand requires greater strength on the part of the performer than in the twohanded case (Giangarra, Conroy, Jobe, Pink and Perry, 1993). This is due to only one upper-limb being used to generate force when swinging the racket and a decreased rotation of the trunk when compared to the two-handed case (Groppel, 1984). There is also general agreement that players performing one-handed backhand groundstrokes are more susceptible to 'tennis elbow' injury due to adverse loading conditions (Bernhang, Dehner and Fogarty, 1974; Blackwell and Cole, 1994; Ginagarra et al., 1993; Roetert, Brody, Dillman, Groppel and Schultheis, 1995).

Despite modern tactics dictating that a variety of backhand strokes are needed during the course of a rally (Elliott et al., 1999), published research has focused on the topspin groundstroke (Blackwell and Cole, 1994; Elliott et al., 1999; Ginagarra et al., 1993; Knudson, 1989; Knudson, 1991; Knudson and Blackwell, 1997; Riek, Chapman and Blackwell, 1999; Wang, 1998). A kinematic comparison of slice backhand groundstrokes performed when the ball bounces high or low found differences such as a more upright trunk when the inbound ball bounces higher (Elliott and Christmass, 1995) although a comparison with a typical topspin backhand groundstroke is currently lacking in the literature. Loading in tennis can be considered as a combination of the internal forces and torques due to the muscles generating joint motion and external forces and torques applied to the system through the ground and tennis racket (Elliott, 2006). It would be of interest to know how the loading on the arm, particularly at the elbow joint, differs between the two strokes. The slice one-handed backhand groundstroke is often considered a defensive stroke with an emphasis on accuracy as opposed to power. It might therefore be expected that the elbow loading is lower than for the seemingly more attacking topspin stroke.

Experimental research in tennis has generally been hampered by the complexity of strokes, the short contact time of the ball on the stringbed (Schlarb, Kneib and Glitsch, 1998) and the inability to practically measure internal loads during tennis strokes. Measurement inaccuracy in kinematic studies due to low frame rates and insufficient camera numbers has typically prevented accurate derivation of joint forces and torques, for example, in the study conducted by Wu, Gross, Prentice and $\mathrm{Yu}$ (2001). Without the use of invasive procedures involving buckle transducers (e.g. Komi, 1992) or fibre optics (e.g. Komi, Belli, Huttunen, Bonnefoy, Geyssant and Lacour, 1996) there is currently no way of accurately determining the actual loads experienced by the subject.

To overcome these problems, computer simulation models have been developed (Glitsch, Schlarb and Baumann, 1999; Nesbit, Elzinga, Herchenroder and Serrano, 2006). The limitations of these models are that potentially important features such as racket frame vibration (Nesbit et al., 2006), variable grip pressure and anatomical damping in the system (Glitsch et al., 2006; Nesbit et al., 2006) have been neglected. The simulated loading within the modelled arm must therefore be considered unrepresentative of the real world situation. More useful models have also incorporated subject-specific parameters to enable simulations to be compared with performances by the subject to provide a quantitative evaluation of the model accuracy (Yeadon and King, 2002; King et al., 2006). In particular for tennis Glynn, King and Mitchell (2011) developed and evaluated an equipment-specific computer simulation model of ball/racket impacts and demonstrated that the model was of a sufficient complexity to accurately represent the responses of the ball, stringbed and racket frame in terms of outbound ball velocity and racket frame linear acceleration. Only when a model has been evaluated in this way can the researcher be confident 
in its capabilities and then use it to address the pertinent research questions (Hubbard, 1993).

The aim of this study was to establish a model capable of estimating with confidence impulsive elbow loading profiles for one-handed tennis backhand groundstrokes capable of identifying under what conditions and strokes there is increased loading at the elbow. This was achieved by developing and evaluating a subject-specific computer simulation model for a one-handed topspin backhand groundstroke and a one-handed slice backhand groundstroke executed by an elite tennis player.

\section{Methods}

A four-segment angle-driven subject-specific computer simulation model of the torso and arm is connected to a previously developed two-segment racket model (Glynn et al., 2011) to simulate one-handed backhand groundstrokes. The resulting model is matched to two contrasting trials by an elite tennis player. A third matched trial is used to help quantify the sensitivity of the model to the grip and wobbling mass parameters along with comparisons to measured racket acceleration and grip torques.

The equations of motion for a 16 degree of freedom 3D computer simulation model of a human arm and torso segment linked to a 13 degree of freedom tennis racket and ball system were developed using Autolev ${ }^{\mathrm{TM}} 3.4$ Professional software package. Rigid hand, forearm, upper-arm, and torso segments of fixed lengths were connected by frictionless pin joints. The rigid segments representing the bones were driven by joint angle-time histories and movement of the thorax centre from the global origin was driven by linear displacement-time histories, obtained from onehanded tennis backhand performances. There were three rotations and three translations specified for the thorax and three rotations specified for the shoulder allowing shoulder flexion/extension, adduction/abduction and internal/external rotation. For the elbow there were two rotations specified allowing elbow flexion/extension and forearm pronation/supination whilst a constant carry angle was specified. Wrist flexion/extension and radial/ulnar deviation were specified with rotations defined in accordance with standard anatomical joint movements (Figure $1(\mathrm{a})$ ). Wobbling mass rigid segments to represent soft tissue motion were attached to the forearm and upper-arm fixed rigid bodies by two identical, 3D non-linear massless spring-damper systems with five degrees of freedom per wobbling mass (Figure 1(b), Yeadon and King, 2008). The restoring force $F_{w}$ in each massless spring-damper was a function of the stiffness $k_{w}$ and damping $c_{w}$ coefficients, the displacement $x$ and velocity $\dot{x}$ of the wobbling segment relative to the fixed rigid component (Equation (1)), based upon the work of Pain and Challis (2001b).

$$
F_{w}=-k_{w} x^{3}-c_{w} \dot{x}
$$




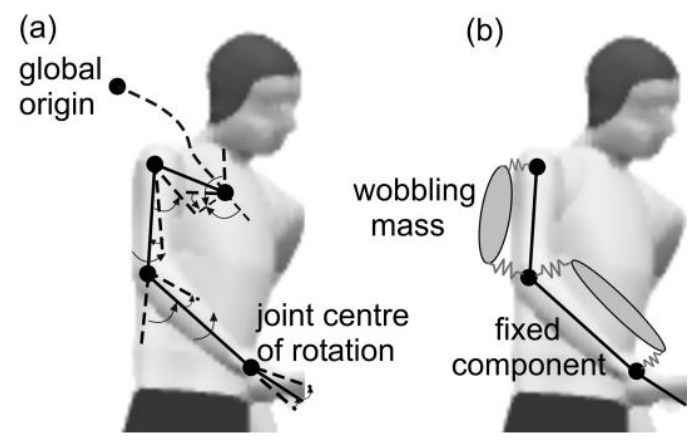

Figure 1. (a) Thorax and joint angle displacements (no degrees of freedom, all values specified from the performance data) and (b) wobbling mass representation (five degrees of freedom per wobbling mass (three translation and two rotation)) in the tennis player computer model.

The upper-limb model was attached to a 13 degree of freedom forward dynamics, equipment-specific computer simulation model of tennis racket/ball impacts (Glynn, King and Mitchell, 2011). The racket frame was represented using two rigid bodies connected by a frictionless pin joint with two linear massless torsional spring-dampers to resist motion in and out of the racket plane and model the fundamental modes of vibration. The stringbed was represented by nine point masses connected using linear massless elastic springs. A point mass representation of the tennis ball allowed normal and oblique impacts to occur at one of the nine specified locations on the stringbed (see Glynn et al., 2011 for further details).

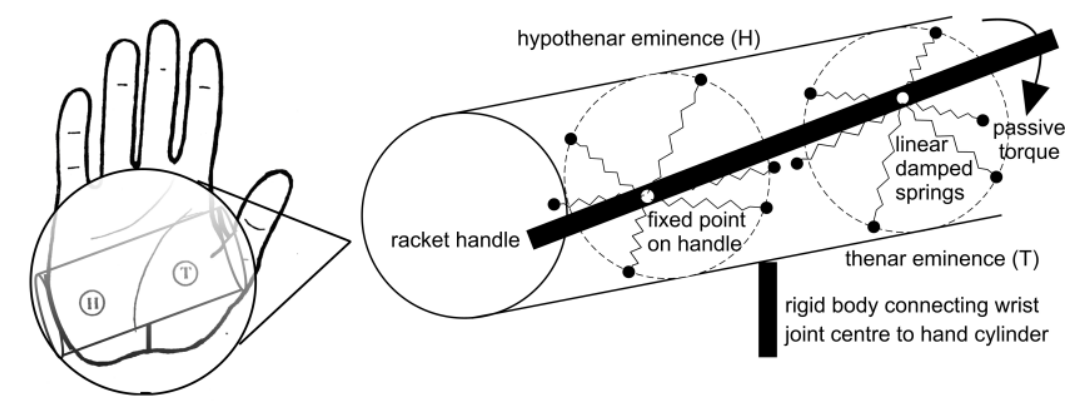

Figure 2. The mechanism for gripping the racket handle at the hypothenar and thenar eminences of the hand (three rotation and three translation degrees of freedom).

The human hand was represented by a rigid segment connecting the wrist joint centre to the proximal end of the metacarpal of the middle finger which was in turn fixed to a rigid, massless cylinder encasing the racket handle. Two points of contact on the racket frame were defined at the hypothenar and thenar eminences, where peak forces occur whilst performing a one-handed topspin backhand groundstroke (Knudson, 1991). Both eminences were modeled as four equidistant points on the circumference of the cylinder and an additional two points along the principle longitudinal axis of the cylinder (Figure 2). Each point was connected to the fixed point on the rigid racket handle by a linear massless spring-damper which applied a gripping force $F_{G}$ (Equation (2)). In total there were six degrees of freedom (three rotation and three translation) between the hand and the racket:

$$
F_{G}=F_{0}-k_{G}\left(L-L_{0}\right)-C_{G} \dot{L}\left(L-L_{0}\right)
$$


where: $F_{0}$ was the initial force acting on the fixed point on the racket handle, $L$ was the length of the spring during the simulation, $L_{0}$ was the initial length of the spring and $\dot{L}$ was the rate of change of the length of the spring with respect to time. The stiffness and damping coefficients were represented by $k_{G}$ and $c_{G}$ respectively. The term ' $L-L_{0}$ ' was used so that the racket had a tendency to come back to its neutral position at the start of the simulation.

Since gripping forces were applied at two single points on the racket handle represented by a rigid rod, a mechanism for modelling resistance to the rotation of the racket handle about its longitudinal axis was necessary. This was achieved by using a linear torsional spring-damper to apply a resistance torque $\mathrm{T}$ about the principle longitudinal axis of the racket where $\mathrm{k}_{T}$ and $\mathrm{c}_{T}$ were the torsional stiffness and damping coefficients respectively (Equation (3)).

$$
\mathrm{T}=-\mathrm{k}_{\mathrm{T}}\left(\theta-\theta_{0}\right)-\mathrm{c}_{\mathrm{T}} \dot{\theta}\left|\theta-\theta_{0}\right|
$$

where: $\theta$ was the angular displacement of the racket handle about its principle longitudinal axis relative to the hand, $\theta_{0}$ was the initial angle at the start of a simulation and $\dot{\theta}$ was the angular velocity of the racket handle relative to the hand. The term ' $\theta-\theta_{0}$ ' was used so that the racket had a tendency to come back to its neutral position at the start of the simulation.

The subject in this study was an elite male, right-handed tennis player with a whole-body mass of $75.5 \mathrm{~kg}$ and a height of $1.86 \mathrm{~m}$. Testing procedures were explained to the subject in accordance with the institution ethical guidelines and a consent form was signed. The kinematics of the subject performing one-handed backhand groundstrokes were automatically tracked using a Vicon 624 motion tracking system. Twelve M2 strobe cameras sampling at a frequency of $250 \mathrm{~Hz}$ were used to calibrate a performance volume of approximately $2.5 \mathrm{~m}^{3}$ and then track the motion of markers attached to the subject and a Head LM 8 tennis racket as he performed one-handed backhand groundstrokes (Figure 3(a)). Reflective markers, $25 \mathrm{~mm}$ in diameter, were placed on the subject in accordance with a Vicon generic marker set to identify joint centres of rotation. Additional markers were placed on the biceps brachii and forearm to approximate wobbling mass displacements and at six locations on the racket frame to measure displacements of the racket relative to the wrist joint centre. Raw kinematic data from the Vicon motion analysis were fitted using quintic splines (Wood and Jennings, 1979) to smooth errors in the data and give time histories that could be used to drive the human component of the model. The closeness of fit at each point was based on the difference between the raw values and the average value from the two adjacent times (Yeadon and King, 2002).

Two genlocked high-speed digital cameras operating at $2500 \mathrm{~Hz}$ were used to measure inbound and outbound ball velocities and impact locations on the stringbed. New Pro Penn Titanium tennis balls were fired from a Bola ball cannon and the subject was asked to perform one-handed topspin and slice groundstrokes as he would normally use during a baseline rally. A trial was considered successful if all data had been captured correctly and the ball landed in a designated target area (Figure 3(b)). A successful topspin and slice trial where the ball impacted at the geometric stringbed centre were chosen for further analysis. In addition a third successful trial (topspin) where the racket was instrumented with uni-axial accelerometers on the racket throat (Brüel and Kjaer charge accelerometers, capturing at a frequency of $2000 \mathrm{~Hz}$ ) and Tekscan pressure sensors positioned 
under the grip on each of the eight 'flats' of the racket handle capturing at a frequency of $250 \mathrm{~Hz}$ was used to allow comparisons of racket frame accelerations and grip torques with the simulation model and also to quantify the sensitivity of the model to the grip parameters used.

(a)

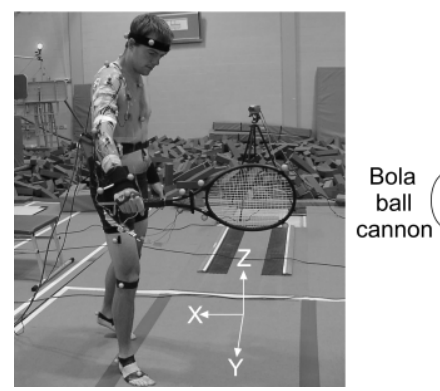

(b)

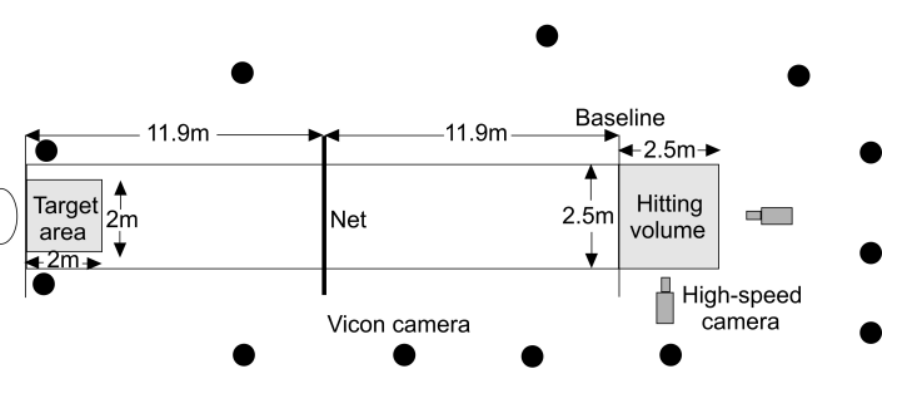

Figure 3. (a) The elite subject with the global reference frame shown and (b) the equipment set-up for analysing one-handed backhand groundstrokes.

Inertia parameters of the subject's body segments were calculated from 95 anthropometric measurements on the subject using a geometric model (Yeadon, 1990). Values for the percentage composition of fat and fat-free mass for the upperarm and forearm segments and whole body masses of cadavers were taken from the literature (Clarys, Martin and Drinkwater, 1984; Clarys and Marfell-Jones, 1986). To relate this information to the elite subject, an estimate of body fat as a percentage of whole body mass was calculated (Withers, Craig, Bourdon and Norton, 1987) based on skinfold measurements at seven sites on the body (Balady, Berra, Golding, Gordon, Mahler and Myers, 2000). The stiffness of the non-linear massless springdampers of the wobbling masses were chosen to match measured displacements of markers on the upper-arm and forearm with simulated wobbling mass displacements, across the one-handed backhand performances. Damping coefficients for the wobbling masses were selected manually so that the system was close to being critically damped (Pain and Challis, 2001a). The sensitivity of the model results to the wobbling mass parameters used was investigated by running simulations with the stiffness and damping parameters for the spring-dampers connecting the wobbling mass segments to the rigid bone segments perturbed by $\pm 10 \%$ along with increasing the parameters by a factor of 10 to mimic a rigid segment condition.

Equipment-specific parameters for the tennis racket frame, stringbed and tennis ball were determined from independent experimental tests (Glynn et al., 2011) and were then fixed. The inertia parameters of the racket frame parts were determined from the results of pendulum oscillation and knife-edge balance experiments. The torsional spring-damper coefficients were optimized using the racket frame model to match experimental acceleration-time histories of a point on the racket frame after being struck by an impact hammer. Spring stiffness coefficients and friction coefficients for the stringbed were optimised using a clamped stringbed model to match experimental coefficient of restitution values and ball rebound angles respectively. Balls were fired at a range of velocities from a pneumatic air cannon to cover the range of relative ball/racket linear velocities $(18 \mathrm{~m} / \mathrm{s}$ to $33 \mathrm{~m} / \mathrm{s})$ measured in the performance data collection. The stiffness and damping coefficients of the normal component of the ball/stringbed impact force were optimised from piezoelectric force plate data after balls were projected from the pneumatic air cannon at the aforementioned velocities (see Glynn et al., 2011 for further details). 
Matching simulations of a topspin and slice trial were determined by varying the visco-elastic parameters of the grip within realistic bounds using the Simulated Annealing optimization algorithm (Corana, Marchesi, Martini and Ridella, 1987) in order to minimize differences in the six degrees of freedom (DOF) between performances and simulations. Linear displacements in the global reference frame of the racket relative to the wrist joint centre and rotations of the racket relative to the hand segment were established by analysing the splined positional data of markers on the wrist, hand and tennis racket. The difference score comprised the root-meansquare (RMS) difference of the three racket angles and three linear racket displacements relative to the hand from the instant of ball contact with the stringbed and every millisecond thereafter for $50 \mathrm{~ms}$. This time period was chosen as it encompassed the ball/stringbed contact phase, the peak grip forces and the racket frame oscillation and decay (Brody, 1989). All six DOF were equally weighted and a $1^{\circ}$ difference in racket angle was assumed to be equivalent to a $1 \mathrm{~cm}$ difference in racket linear displacement. The ball/stringbed contact time and the outbound ball velocity were compared for the matching simulations and corresponding performances. Elbow flexion/extension and pronation/supination joint torques along with the internal joint reaction force at the elbow were calculated and compared for the two matching simulations for the period from ball impact until $50 \mathrm{~ms}$ afterwards. In addition the peak torques calculated for the one-hand backhand groundstrokes at the elbow for flexion / extension were compared with estimated maximal strength values obtained from torque measurements on the same participant using an isovelocity dynamometer (King and Yeadon, 2002).

The third recorded trial was matched using the same methodology. The measured racket acceleration and grip torques were then compared to the matched simulation. The sensitivity of the model to the grip parameters was investigated by swapping the grip parameters for the two matched topspin trials and observing the effect on each matching simulation. In addition the grip parameters were increased by a factor of 10 to mimic a rigid grip condition and the effect on the elbow loading quantified.

\section{Results}

The inbound ball velocities at the instant of contact with the stringbed were $10.0 \mathrm{~m} / \mathrm{s}$ (global $Y$ axis; anterior-posterior) and $-1.4 \mathrm{~m} / \mathrm{s}$ (global $Z$ axis; vertical) for the topspin trial. The corresponding values for the slice trial were $-10.0 \mathrm{~m} / \mathrm{s}$ and -1.6 $\mathrm{m} / \mathrm{s}$ respectively indicating consistent ball velocity at the point of impact from the experimental procedure. The relative ball/racket velocities of both strokes at initial ball impact with the stringbed were similar (Table I) with respect to the fixed global $X$, $Y$ and $Z$ axes indicated on Figure 3(a). Notable differences were seen in the relative ball/racket linear velocity along the $Z$ axis (vertical) as the racket moved in the positive $Z$ direction to generate topspin whilst the racket movement was in the opposite direction for the slice trial. Around the global $X$ axis for the slice stroke, the racket face angle was almost $15^{\circ}$ 'more open' than for the topspin trial to facilitate the generation of backspin on the ball. Wrist and elbow joint angle-time histories appeared similar for the two trials over the period of most interest, $50 \mathrm{~ms}$ after ball impact, with RMS differences of $7^{\circ}$ and $5^{\circ}$ respectively (Figure 4). The shoulder joint angle-time histories, particularly flexion/extension angles, showed distinct differences with a RMS difference of $16^{\circ}$ over the same time period (Figure 4). For the topspin 
trial there was flexion of the shoulder joint through impact whilst for the slice trial the subject 'chopped' down on the ball by extending at the shoulder joint to generate backspin as has been previously observed (Elliott and Christmass, 1995).

Table I. Relative global impact conditions

\begin{tabular}{ccccc}
\hline \multirow{2}{*}{ trial } & impact condition & \multicolumn{3}{c}{ global axis } \\
& & $\mathrm{X}$ & $\mathrm{Y}$ & $\mathrm{Z}$ \\
\hline \multirow{2}{*}{ topspin } & ball/racket velocity $(\mathrm{m} / \mathrm{s})$ & -0.5 & 30.9 & 3.2 \\
& racket angles & $-203^{\circ}$ & $-9^{\circ}$ & $-90^{\circ}$ \\
\multirow{2}{*}{ slice } & ball/racket velocity $(\mathrm{m} / \mathrm{s})$ & 4.1 & 28.6 & -9.1 \\
& racket angles & $-188^{\circ}$ & $-16^{\circ}$ & $-91^{\circ}$ \\
\hline
\end{tabular}

(a)

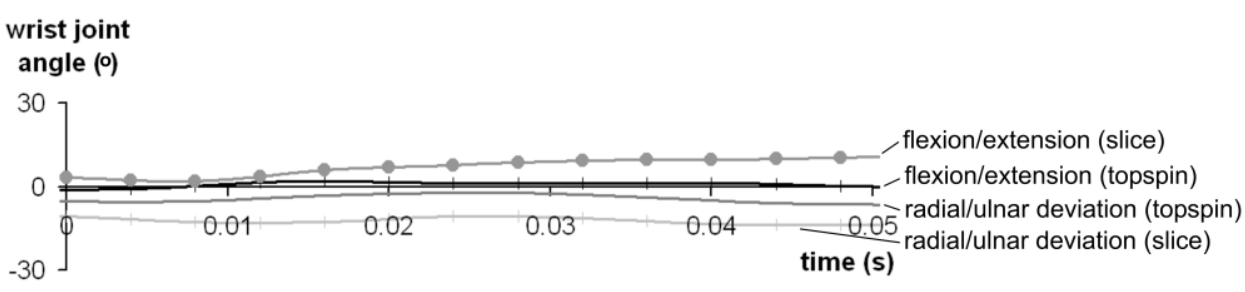

(b)

\section{elbow joint} angle (o)

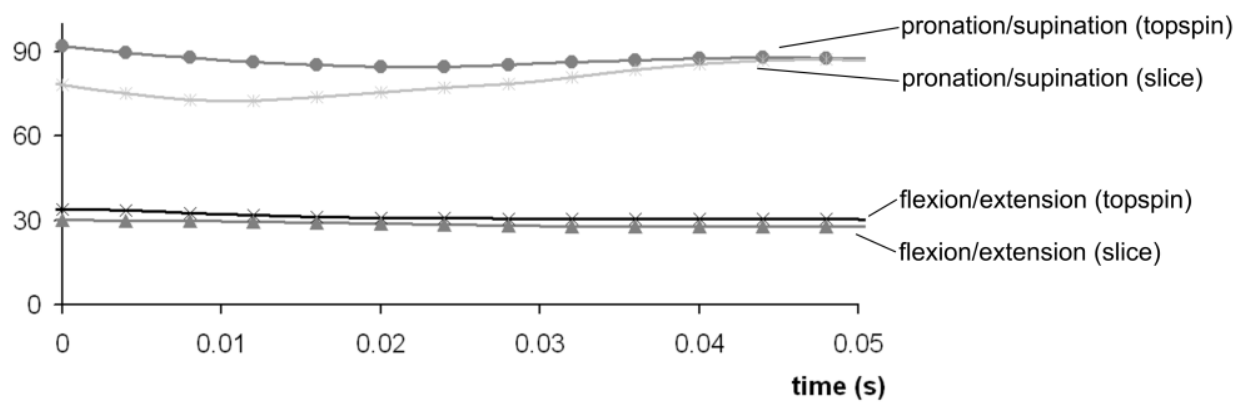

(c) shoulder joint

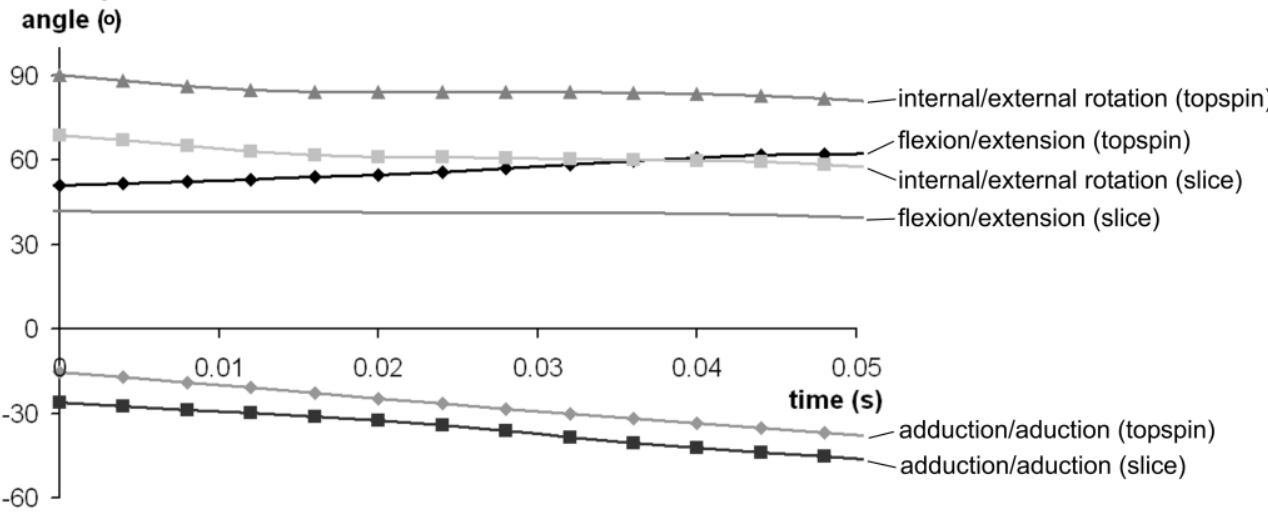

Figure 4. The splined angle-time histories of the (a) wrist, (b) elbow and (c) shoulder joints for the topspin and slice trials.

Subject-specific segmental inertia parameters were calculated (Table II) along with a calculated body fat composition of $8.4 \%$ from which the rigid fixed and wobbling mass inertia parameters were calculated (Table III). The stiffness 
coefficients for the wobbling mass spring-dampers were $2 \times 10^{7} \mathrm{~N} / \mathrm{m}^{3}$ and $3 \times 10^{7} \mathrm{~N} / \mathrm{m}^{3}$ for the upper-arm and forearm respectively. The damping coefficients were $95 \mathrm{Ns} / \mathrm{m}$ and $120 \mathrm{Ns} / \mathrm{m}$ for the upper-arm and forearm respectively. The increase in forearm muscle tension as a result of gripping the tennis racket handle and a less massive wobbling component with lower moment of inertia (MOI) about each axis are considered contributing factors to these differences.

Table II. Segmental inertia parameters for the upper-limb of the tennis player

\begin{tabular}{|c|c|c|c|c|c|c|}
\hline \multirow{2}{*}{ segment } & \multirow{2}{*}{$\begin{array}{c}\operatorname{mass} \\
(\mathrm{kg})\end{array}$} & \multirow{2}{*}{$\begin{array}{l}\text { distance } \\
\text { (m) }\end{array}$} & \multirow{2}{*}{$\begin{array}{l}\text { segment length } \\
(\mathrm{m})\end{array}$} & \multicolumn{3}{|c|}{$\mathrm{MOI}\left(\mathrm{kg} \cdot \mathrm{m}^{2}\right)$} \\
\hline & & & & $I_{x}$ & $\mathrm{I}_{\mathrm{y}}$ & $\mathrm{I}_{\mathrm{z}}$ \\
\hline upper-arm & 2.18 & 0.147 & 0.338 & 0.01694 & 0.01694 & 0.00258 \\
\hline forearm & 1.52 & 0.124 & 0.296 & 0.01009 & 0.01017 & 0.00121 \\
\hline hand & 0.40 & 0.050 & $0.080 .098^{1} 0.05^{2}$ & 0.00045 & 0.00054 & 0.00054 \\
\hline
\end{tabular}

Nomenclature: distance refers to the distance of COM from proximal joint, ${ }^{1}$ segment depth, ${ }^{2}$ segment width, $I_{x}, I_{y}$, and $I_{z}$ refer to moments of inertia (MOls) about the lateral, frontal and longitudinal axes respectively through the centre of mass (COM) of body segments.

Table III. Segmental inertia parameters for the rigid fixed and wobbling mass components

\begin{tabular}{|c|c|c|}
\hline parameter & upper-arm & forearm \\
\hline mass of fixed component, $\mathrm{m}_{\mathrm{f}}(\mathrm{kg})$ & 0.426 & 0.295 \\
\hline mass of wobbling component, $\mathrm{m}_{\mathrm{w}}(\mathrm{kg})$ & 1.755 & 1.237 \\
\hline $\begin{array}{l}\text { MOI of fixed component about lateral } \\
\text { and frontal axes, } I_{\text {lff }}\left(\mathrm{kg} \cdot \mathrm{m}^{2}\right)\end{array}$ & 0.0030 & 0.0020 \\
\hline $\begin{array}{l}\text { MOI of wobbling component about } \\
\text { lateral and frontal axes, } I_{\text {lfw }}\left(\mathrm{kg} \cdot \mathrm{m}^{2}\right)\end{array}$ & 0.0140 & 0.0080 \\
\hline $\begin{array}{l}\text { MOI of fixed component about } \\
\text { longitudinal axis, } \mathrm{I}_{\mathrm{ff}}\left(\mathrm{kg} \cdot \mathrm{m}^{2}\right)\end{array}$ & 0.0005 & 0.0002 \\
\hline $\begin{array}{l}\text { MOI of wobbling component about } \\
\text { longitudinal axis, } I_{\mathrm{I}}\left(\mathrm{kg} \cdot \mathrm{m}^{2}\right)\end{array}$ & 0.0025 & 0.0008 \\
\hline $\begin{array}{l}\text { mass centre of fixed component from } \\
\text { proximal joint centre, } x_{f}(m)\end{array}$ & 0.145 & 0.148 \\
\hline $\begin{array}{l}\text { mass centre of wobbling component } \\
\text { from proximal joint centre, } x_{w}(m)\end{array}$ & 0.121 & 0.118 \\
\hline segment length, $L$ (m) & 0.289 & 0.296 \\
\hline
\end{tabular}

The grip parameters were determined from the matching procedure of the two trials with RMS differences of $0.1^{\circ}$ and $0.3^{\circ}$ in racket kinematics obtained for the topspin and slice trials respectively (Table IV). Optimal grip parameter values were of the same order of magnitude for the topspin and slice trials suggesting that for the elite subject in this study gripping technique did not vary considerably between the 
two strokes. Just after ball impact, the model accurately simulated the linear and angular displacements of the racket relative to the wrist joint centre (Table IV, Figure 5). In addition the ball/stringbed contact time for the matching simulations were less than a tenth of a millisecond different to the values measured from both the topspin and slice trials (Table V) and the outbound ball velocities for the matching simulations were $7.5 \%$ and $3.5 \%$ different to the values measured from the topspin and slice trials respectively.

Table IV. Grip parameters for the two matching simulations

\begin{tabular}{|c|c|c|}
\hline parameter & topspin & slice \\
\hline damping coefficient for hypothenar eminence, $\mathrm{C}_{\mathrm{GH}}\left(\mathrm{Ns} / \mathrm{m}^{2}\right)$ & 574000 & 553500 \\
\hline damping coefficient for thenar eminence, $\mathrm{C}_{\mathrm{GT}}\left(\mathrm{Ns} / \mathrm{m}^{2}\right)$ & 579000 & 82600 \\
\hline damping coefficient for torsional spring-damper, $\mathrm{C}_{\top}\left(\mathrm{Nms} / \mathrm{rad}^{2}\right)$ & 10.8 & 30.1 \\
\hline stiffness coefficient for hypothenar eminence, $\mathrm{k}_{\mathrm{GH}}(\mathrm{N} / \mathrm{m})$ & 74000 & 115300 \\
\hline stiffness coefficient for thenar eminence, $\mathrm{k}_{\mathrm{GT}}(\mathrm{N} / \mathrm{m})$ & 76300 & 60400 \\
\hline stiffness coefficient for torsional spring-damper, $\mathrm{k}_{\mathrm{T}}(\mathrm{Nm} / \mathrm{rad})$ & 99.0 & 29.1 \\
\hline initial force at hypothenar eminence, $\mathrm{F}_{\mathrm{OH}}(\mathrm{N})$ & 10.0 & 13.2 \\
\hline initial force at thenar eminence, $\mathrm{F}_{0 T}(\mathrm{~N})$ & 10.0 & 12.3 \\
\hline RMS difference $\left(^{\circ}\right)$ & 0.1 & 0.3 \\
\hline
\end{tabular}

Table V. A comparison of performance and simulation outbound ball velocities / contact times with the stringbed

\begin{tabular}{cccc}
\hline & & topspin & slice \\
\hline outbound ball & performance & 31.6 & 27.9 \\
velocity $(\mathrm{m} / \mathrm{s})$ & simulation & 29.2 & 28.2 \\
& performance & 4 & 4 \\
ball/stringbed & simulation & 4 & 4 \\
\hline
\end{tabular}

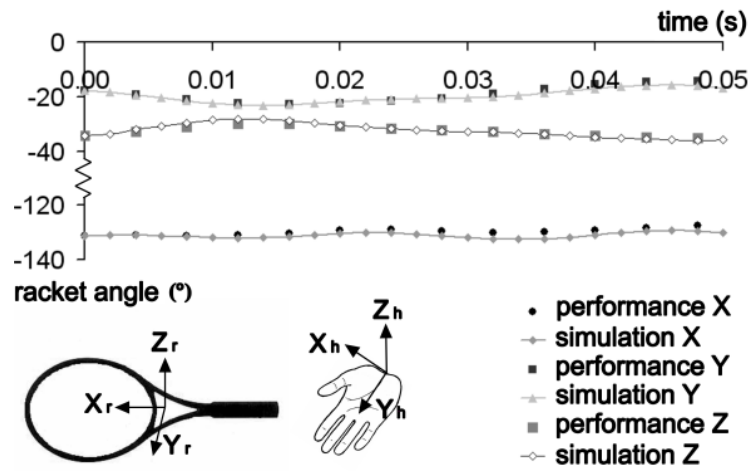

Figure 5. Matching the three rotational DOF of the racket relative to the hand for the topspin trial. 
The joint torque and internal joint reaction forces at the elbow were comparable across the topspin and slice trials in terms of the magnitude, timing and rate of decay of the loading over the specified time period from ball impact (Figure 6). Joint torque and force-time histories were characterised by an initial impulsive loading peak just after the ball left the stringbed, approximately $5 \mathrm{~ms}$ after first contact (Figure 6). The ball/stringbed contact force-time history peaked at almost $800 \mathrm{~N}, 2 \mathrm{~ms}$ after initial contact for both trials. It would appear that an attenuated form of this impulse is evident at the elbow, delayed by some 2-3 ms.

Small increases in the magnitudes of peak flexion/extension joint torque (4\%) and peak internal joint reaction force $(1 \%)$ and a small decrease in the magnitude of peak pronation/supination joint torque $(6 \%)$ were found when performing a slice as opposed to a topspin backhand groundstroke (Table VI). Proportionately larger increases in the net impulsive flexion/extension torque necessary to stabilise the racket after impact were evident in the slice stroke after the initial peak (15-35 ms after impact, Figure 6(a)). Similarly, the elbow joint reaction force was higher for the slice backhand than for the topspin stroke for this pair of shots $(10-25 \mathrm{~ms}$, Figure $6(b))$. Further examination of Figure 6(a) reveals that the only other observed difference between the loading characteristics of these particular topspin and slice shots was an elevated loading rate (shock) experience at the elbow for pronation/ supination with the topspin stroke $(0-5 \mathrm{~ms}$ Figure $6(\mathrm{a}))$.

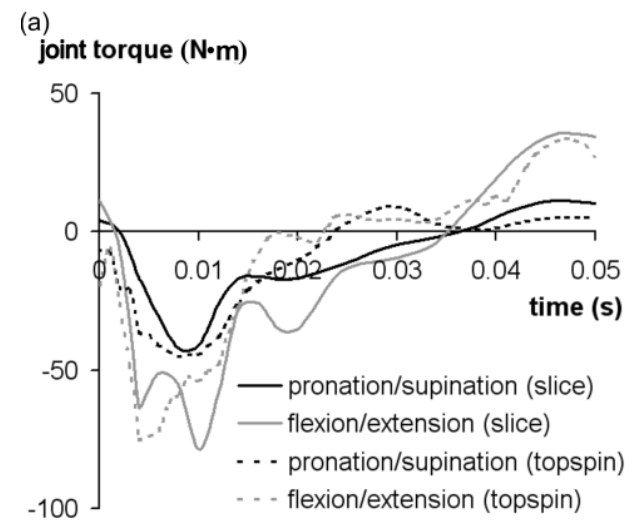

(b)

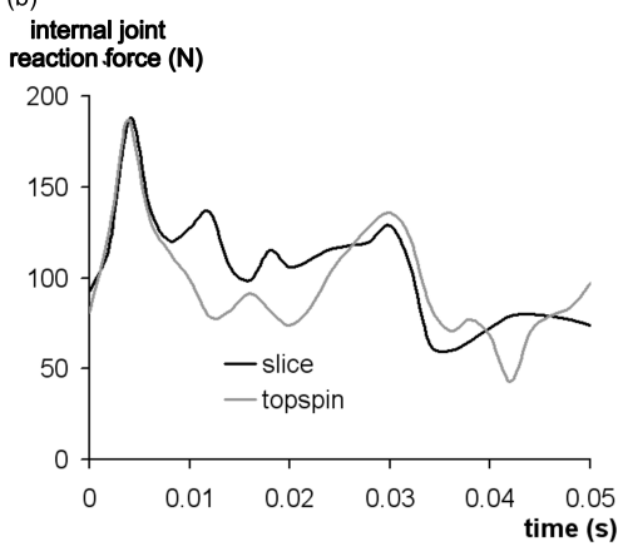

Figure 6. The simulated (a) joint torque and (b) internal joint reaction force -time histories at the elbow for the matching topspin and slice simulations. 
Table VI. A comparison of peak elbow loading for the topspin and slice trials

\begin{tabular}{ccc}
\hline loading & topspin & slice \\
\hline $\begin{array}{c}\text { peak flexion/extension } \\
\text { joint torque }(\mathrm{Nm})\end{array}$ & -75 & -78 \\
$\begin{array}{c}\text { peak pronation/supination } \\
\text { joint torque }(\mathrm{Nm})\end{array}$ & -45 & -42 \\
$\begin{array}{c}\text { peak internal joint } \\
\text { reaction force }(\mathrm{N})\end{array}$ & 186 & 189 \\
\hline
\end{tabular}

For the third matched trial racket frame accelerations (in and out of the plane of the racket) and net torques about the centre of the handle were compared (Figure 7 and Figure 8). Swapping the grip parameters for the two matched topspin trials resulted in a small increase of less than a $1^{\circ}$ in the RMS difference between each simulation and the recorded performance (Table VII) along with less than $1 \mathrm{Nm}$ difference in peak elbow torques and less than $2 \mathrm{~N}$ difference in peak internal joint reaction force. Increasing the grip stiffness and damping parameters by a factor of 10 resulted in peak torques that were more than double the original matched values and peak elbow internal joint reaction forces that were 1.8 times the matched values. A $10 \%$ increase in the wobbling mass visco-elastic parameters resulted in $2 \%$ decrease in the maximum displacement of the wobbling mass relative to the rigid segment, less than a $1 \%$ increase in the peak force in the wobbling mass springdamper and no observable effect on the loading at the elbow while increasing the wobbling mass stiffness and damping parameters by a factor of 10 resulted in less than $1 \%$ difference in elbow loading.

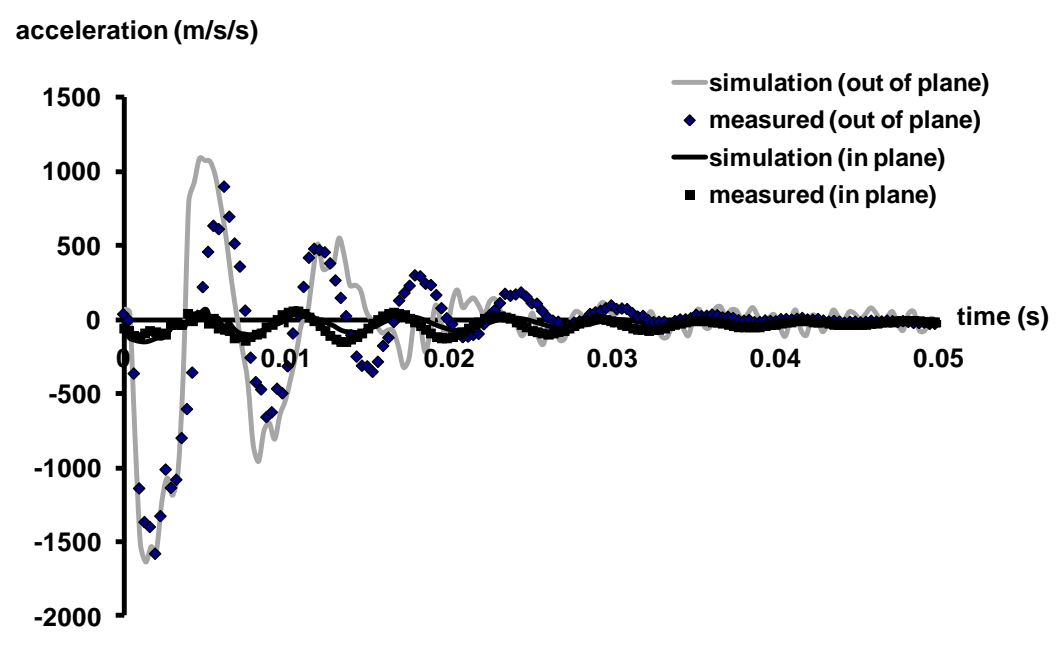

Figure 7. Comparison of measured and matching simulation racket frame accelerations in and out of the plane of the racket. 


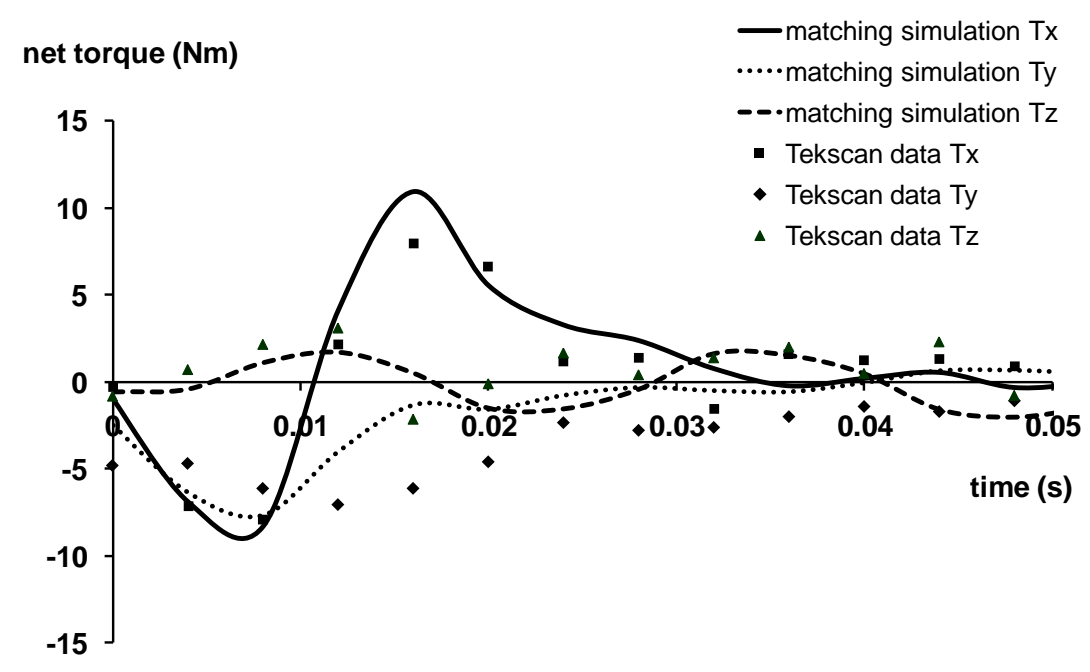

Figure 8. Comparison of the measured net torques about the centre of the handle (calculated from measured Tekscan pressure data) and the equivalent matched simulation.

Table VII. Effect of swapping the grip parameters on the RMS difference for the two matched topspin trials

\begin{tabular}{ccc}
\hline trial & original & swapped \\
\hline topspin & $0.1^{\circ}$ & $0.8^{\circ}$ \\
$2^{\text {nd }}$ topspin & $0.5^{\circ}$ & $1.0^{\circ}$ \\
\hline
\end{tabular}

Note: original parameter values for the second matched topspin trial were: $\mathrm{C}_{\mathrm{GH}}=453000 \mathrm{Ns} / \mathrm{m}^{2}, \mathrm{c}_{\mathrm{GT}}=473000$ $\mathrm{Ns} / \mathrm{m}^{2}, \mathrm{c}_{\mathrm{T}}=0.8 \mathrm{Nms} / \mathrm{rad}^{2}, \mathrm{k}_{\mathrm{GH}}=101000 \mathrm{~N} / \mathrm{m}, \mathrm{k}_{\mathrm{GT}}=$ $94800 \mathrm{~N} / \mathrm{m}, \mathrm{k}_{\mathrm{T}}=30.0 \mathrm{Nm} / \mathrm{rad}, \mathrm{F}_{O \mathrm{H}}=18.7 \mathrm{~N}$ and $\mathrm{F}_{0 \mathrm{~T}}=$ $10.1 \mathrm{~N}$.

A peak elbow extension torque of $74 \mathrm{Nm}$ and peak elbow pronation torque of 24 $\mathrm{Nm}$ were obtained from strength measurements with the participant used in this study. The peak torques calculated from the one handed backed ground strokes were similar for elbow extension but higher for elbow supination (Table VI).

\section{Discussion and implications}

The novel approach of combining a subject-specific angle-driven computer model of a tennis player, with a previously developed forward dynamics, equipmentspecific computer model of tennis racket/ball impacts (Glynn et al., 2011) has been used to investigate loading at the elbow in a topspin and slice one-handed backhand groundstroke performed by an elite tennis player. The two ground strokes selected were typical trials by the elite player and are comparable with reported studies of the backhand (Riek et al., 1999, Knudson \& Blackwell, 1997). The model can be used to calculate peak force, impulse and shock loading with sufficient confidence to compare different strokes. Simulation results suggest that although some small differences were detectable for well executed one-handed backhand slice and topspin groundstrokes, there was no notable change in peak elbow loading. Further research to investigate impulsive loads experienced by other demographic groups such as recreational players who are more prone to elbow injury is now possible. 
Customizing the simulation model to a specific individual through determining subject-specific model parameters and obtaining two matching simulations has demonstrated that the model has sufficient justifiable complexity without being overly complex to simulate backhand strokes. In particular to take into account soft tissue movement in the forearm and upper arm wobbling mass elements have been incorporated and for the grip to allow relative motion between the hand and racket a six degree of freedom grip representation has been used. Both these added features are justifiable as they address specific characteristics of the arm-racket system and are improvements on previous models of tennis strokes. Ball/stringbed contact time and outbound ball velocities for the two matching simulations (Table V) were in close agreement with measured values despite neither variable being directly matched in the optimization procedure. This provides additional strong evidence that appropriate model parameters / model complexity (including improved grip simulation) and matching simulations were found with the two trials being accurately simulated by the computer model. In addition, for the third matched trial good agreement was observed for racket frame acceleration and net grip torques (Figures 7 and 8) demonstrating that the grip equations and input to hand from the racket model were appropriate.

The sensitivity of the model to the grip and wobbling mass visco-elastic parameters was investigated through running simulations with the parameters varied. In particular the grip parameters were swapped between the two matched topspin simulations and the wobbling mass parameters were perturbed by $\pm 10 \%$. The simulation results were found to be insensitive to the visco-elastic parameters used with small differences in racket displacements and elbow loading observed. As a consequence the simulation model has not been 'overly tuned' in order to match the recorded performances. In addition the grip and wobbling mass parameters were increased by a factor of 10 to simulate a rigid grip and rigid segment situations. Resulting simulations were sensitive to the grip conditions but not sensitive to the wobbling mass movement suggesting that it is crucial to get grip conditions appropriately modelled but wobbling mass representations may not be necessary for simulating backhand strokes. The lack of sensitivity to the wobbling mass parameters warrants further investigation as in landings accounting for soft tissue motion has been shown to have a substantial effect on joint torques and loads (Pain and Challis, 2006). For example the assumption of rigid pin joints and lack of joint compression at the wrist and elbow might need to be considered. The importance of a realistic grip representation is supported by experimental studies on the coupling of the hand and racket where it has been demonstrated that a rigid connection is not realistic (Brody, 1989; Hatze, 1992; Kawazoe, 1997; Knudson, 1997; Hennig, 2007). The magnitude of the elbow torques calculated for the backhand strokes were compared with strength measurements taken on the subject. For elbow extension good agreement in the maximum elbow torques was found, while for elbow supination the torques calculated for using the simulation model were larger than the torques measured on the isovelocity dynamometer. Furthermore, the elbow torques are of the same order of magnitude to those reported in other tennis strokes (Bahamonde and Knudson, 2003; Nesbit et al., 2006). Overall, the agreement between simulation and recorded performance was good, the results were insensitive to the parameters used, and the calculated elbow loads have been shown to be reasonable. As a consequence, the model can be used with confidence to investigate the technique used in these two tennis strokes and the loads applied to the arm. 
The present study has focused on an elite male tennis player and two, onehanded backhand performances. It has been demonstrated that the joint torques and internal joint reaction forces at the elbow were comparable across the topspin and slice trials (Figure 6). A clear peak in the elbow loading is evident a few milliseconds after ball impact that is arguably linked to the impulsive torque experienced in the hand (Figure 8 ) and this has previously been identified as a likely mechanism of elbow injury (Knudson, 1991). In the future, an in depth analysis of one-handed backhand technique and the associated elbow loading is now possible with more trials of additional subjects, male and female, of varying ages and abilities. Since the human arm model is angle driven, it is essentially equivalent to an inverse dynamics analysis incorporating the effect of soft tissue motion and enables net impulsive internal joint loads to be estimated using a subject and equipment-specific computer simulation model.

To determine individual extensor/flexor torques or to examine the effect of muscle co-contraction on internal reaction forces (Mills, Pain and Yeadon, 2008) would require more complex torque / muscle driven simulation models respectively along with accurate measures of muscle activity. These more complex models would provide additional useful information but would also require substantial increases in computational overhead. The assumption of rigid pin joints and lack of joint compression at the wrist and elbow could also be addressed by incorporating additional visco-elastic elements. Furthermore, to observe the transmission of force through the arm in more detail, a finite element model of the arm (e.g. Ng-Thow-Hing and Fiume, 1999) and the ball/racket system would be needed, increasing the complexity of the system considerably. In time, this level of complexity may be possible, but it is beyond the scope of the present study which provides a useful tool for examining net internal loading during tennis strokes to be calculated.

\section{Conclusion}

A computer simulation model for one-handed backhand groundstrokes has been customised to an elite tennis player through determining subject-specific parameters. Where possible, parameters were determined by direct measurement. Experimental results and data from the literature were used to determine remaining parameters from a matching optimisation process. Evaluation of the model showed excellent agreement between two contrasting one-handed backhand performances and their matching simulations with RMS differences of $0.1^{\circ}$ and $0.3^{\circ}$ for the topspin and slice trials respectively based on racket kinematics. Simulated ball/stringbed contact time and outbound ball velocity were found to be less than $8 \%$ different from the values measured experimentally for both trials, once all model parameters had been determined and then fixed. Simulation results suggest that for similar relative impact conditions, the difference in elbow loading for a topspin and slice groundstroke was small with less than $6 \%$ difference in peak loading values. The angle-time histories at the wrist and elbow joints for the $50 \mathrm{~ms}$ just after ball impact were similar for the two trials with RMS differences of $7^{\circ}$ and $5^{\circ}$ respectively, which may in part explain this finding. This study provides a basis for further investigation of the factors that may increase elbow loading during tennis strokes. 


\section{Acknowledgements}

The authors would like to acknowledge Head AG and the UK EPSRC for supporting this research.

\section{References}

Bahamonde, R.E., \& Knudson, D. (2003). Kinetics of the upper extremity in the open and square stance tennis forehand. Journal of Science and Medicine in Sport, 6, 88-101.

Balady, G.J., Berra, K.A., Golding, L.A., Gordon, N.F., Mahler, D.A., Myers, J.N., (2000). ACSM'S Guidelines for exercise testing and prescription (Sixth Edition). Philadelphia, Pennsylvania: Lippincott, Williams and Wilkins.

Bernhang, A.M., Dehner, W., \& Fogarty, C. (1974). Tennis elbow: a biomechanical approach. Journal of Sports Medicine, 2, 235-260.

Blackwell, J.R., \& Cole, K.J. (1994). Wrist kinematics differ in expert and novice tennis players performing the backhand stroke: implications for tennis elbow. Journal of Biomechanics, 27, 509-516.

Brody, H. (1989). Vibration damping of tennis rackets. International Journal of Sport Biomechanics, 5, 451-456.

Clarys, J.P., Martin, A.D., \& Drinkwater, D.T. (1984). Gross tissue weights in the human body by cadaver dissection. Human Biology, 56, 459-473.

Clarys, J.P., \& Marfell-Jones, M.J. (1986). Anthropometric prediction of component tissue masses in the minor limb segments of the human body. Human Biology, 58, 761-769.

Corana, A., Marchesi, M., Martini, C., \& Ridella, S. (1987). Minimizing multimodal functions of continuous variables with the "Simulated Annealing" algorithm. ACM Transactions on Mathematical Software, 13, 262-280.

Elliott, B.C., Marsh, A.P., \& Overheu, P.R. (1989). The topspin backhand drive in tennis: a biomechanical analysis. Journal of Human Movement Studies, 16, 116.

Elliott, B.C., \& Christmass, M. (1995). A comparison of the high and low backspin backhand drives in tennis using different grips. Journal of Sports Sciences, 13, 141-151.

Elliott, B.C. (2006). Biomechanics and tennis. British Journal of Sports Medicine, 40, 392-396.

Giangarra, C.E., Conroy, B., Jobe, F.W., Pink, M., Perry, J. (1993). Electromyographic and cinematographic analysis of elbow function in tennis players using single- and double-handed backhand strokes. American Journal of Sports Medicine, 21, 394-399.

Glitsch, U., Schlarb, H., \& Baumann, W. (1999). Embedding of flexible bodies into a dynamic simulation of the tennis stroke. In T. van den Bogert, G. Cole and R. Neptune (Eds.), Proceedings of the VII International Symposium on Computer Simulation in Biomechanics (pp. 14-17). Canada: University of Calgary.

Glynn, J.A., King, M.A., \& Mitchell, S.R. (2011). A computer simulation model of tennis racket/ball impacts. Sports Engineering, 13, 65-72. 
Groppel, J.L. (1984). Tennis for Advanced Players (and those who would like to be). Champaign, IL: Human Kinetics.

Hubbard, M. (1993). Computer simulation in sport and industry. Journal of Biomechanics, 26, 53-61.

King, M.A., Wilson, C. \& Yeadon, M.R. (2006). Evaluation of a torque-driven model of jumping for height. Journal of Applied Biomechanics, 22, 264-274.

King, M.A. \& Yeadon, M.R. (2002). Determining subject-specific torque parameters for use in a torque-driven simulation model of dynamic jumping. Journal of Applied Biomechanics, 18, 207-217.

Knudson, D.V. (1989). Hand forces and impact effectiveness in the tennis backhand. Journal of Human Movement Studies, 17, 1-7.

Knudson, D.V. (1991). Forces on the hand in the tennis one-handed backhand. International Journal of Sport Biomechanics, 7, 282-292.

Knudson, D.V., \& Blackwell, J. (1997). Upper extremity angular kinematics of the one-handed backhand drive in tennis players with and without tennis elbow. International Journal of Sports Medicine, 18, 79-82.

Komi, P.V. (1992). Stretch-shortening cycle. In P.V. Komi (Ed.), Strength and Power in Sport (169-179). Oxford: Blackwell Scientific Publishers.

Komi, P.V., Belli, A., Huttunen, V., Bonnefoy, R., Geyssant, A. Lacour, J.R. (1996). Optic fibre as a transducer of tendomuscular forces. European Journal of Applied Physiology, 72, 278-280.

Mills, C., Pain, M.T.G., \& Yeadon, M.R. (2008). The influence of simulation model complexity on the estimation of internal loading in gymnastics landings. Journal of Biomechanics, 41, 620-628.

Nesbit, S.N., Elzinga, M., Herchenroder, C., Serrano, M. (2006). The effects of racket inertia tensor on elbow loadings and racket behaviour for central and eccentric impacts. Journal of Sports Science and Medicine, 5, 304-317.

Ng-Thow-Hing, V., \& Fiume, E. (1999). B-spline solids as physical and geometric muscle models for musculoskeletal systems. In T. van den Bogert, G. Cole \& R. Neptune (Eds.), Proceedings of the VII International Symposium on Computer Simulation in Biomechanics (pp. 68-71). Canada: University of Calgary.

Pain, M.T.G., \& Challis, J.H. (2001a). High resolution determination of body segment inertial parameters and their variation due to soft tissue motion. Journal of Applied Biomechanics, 17, 326-334.

Pain, M.T.G., \& Challis, J.H. (2001b). The role of the heel pad and shank soft tissue during impacts: A further resolution of a paradox. Journal of Biomechanics, 343, 327-333.

Pain, M.T.G., \& Challis, J.H. (2006). The influence of soft tissue movement on ground reaction forces, joint torques and joint reaction forces in drop landings. Journal of Biomechanics, 39, 119-124.

Riek, S., Chapman, A.E., \& Milner, T. (1999). A simulation of muscle force and internal kinematics of extensor carpi radialis brevis during backhand tennis stroke: implications for injury. Clinical Biomechanics, 14, 477-483. 
Roetert, E.P., Brody, H., Dillman, C.J., Groppel, J.L., Schultheis, J.M. (1995). The biomechanics of tennis elbow. An integrated approach. Clinics in Sports Medicine, 14, 47-57.

Roetert, E.P., \& Groppel, J.L. (2001). World-Class Tennis Technique. Leeds: Human Kinetics.

Schlarb, H., Kneib, B., \& Glitsch, U. (1998). Modelling of the elastic racket properties in the dynamic computer simulation of tennis. In H. Riehle \& M Vieten (Eds.), Proceedings of the XVI International Symposium on Biomechanics in Sports (pp. 379-382). Germany: Universitätsverlag Konstanz.

Wang, L. (1998). Kinematics of upper limb and trunk in tennis players using single handed backhand strokes. In $\mathrm{H}$. Riehle \& M Vieten (Eds.), Proceedings of the XVI International Symposium on Biomechanics in Sports (pp. 273-276). Germany: Universitätsverlag Konstanz.

Wilson, C., King, M.A., \& Yeadon, M.R. (2006). Determination of subject-specific model parameters for visco-elastic elements. Journal of Biomechanics, 39, 1883-1890.

Withers, R.T., Craig, N.P., Bourdon, P.C., Norton, K.I. (1987). Relative body fat and anthropometric prediction of body density of male athletes. European Journal of Applied Physiology, 56, 191-200.

Wood, G.A., \& Jennings, L.S. (1979). On the use of spline functions for data smoothing. Journal of Biomechanics, 12, 477-479.

Wu, S.K., Gross, M.T., Prentice, W.E., Yu, B. (2001). Comparison of ball-and-racket impact force between two tennis backhand stroke techniques. Journal of Orthopaedic and Sports Physical Therapy, 31, 247-254.

Yeadon, M.R. (1990). The simulation of aerial movement - II: A mathematical inertia model of the human body. Journal of Biomechanics, 23, 67-74.

Yeadon, M.R., \& King, M.A. (2002). Evaluation of a torque driven simulation model of tumbling. Journal of Applied Biomechanics, 18, 195-206.

Yeadon, M.R., \& King, M.A. (2008). Computer simulation modelling in sport. In C.J. Payton \& R.M. Bartlett (Eds.), Biomechanical Evaluation of Movement in Sport and Exercise: BASES Guidelines (pp. 176-205). London: Routledge. 